\title{
INFLUÊNCIA DO PRÉ-TRATAMENTO DA MATÉRIA- PRIMA NA OBTENÇÃO DE ÓLEO ESSENCIAL DE FRUTOS DE AROEIRA-VERMELHA (Schinus terebinthifolius Raddi)
}

\author{
M. G. A. MAGGIERI ${ }^{1}$, B. G. SILVA ${ }^{1}$ e A. M. F. FILETI ${ }^{1}$ \\ ${ }^{1}$ Universidade Estadual de Campinas, Faculdade de Engenharia Química \\ E-mail para contato: b.guzzos@gmail.com
}

\begin{abstract}
RESUMO - Este trabalho teve por objetivo avaliar a influência da secagem da matéria-prima na obtenção de óleo essencial de frutos da aroeira-vermelha (Schinus terebinthifolius Raddi). Os frutos foram secos em estufa $\left(40,0{ }^{\circ} \mathrm{C}\right)$ e triturados e em seguida submetidos ao método de hidrodestilação em Clevenger. Os resultados revelaram que os maiores rendimentos do óleo essencial foram obtidos quando se utilizou os frutos in natura. A análise decromatografia gasosa acoplada à espectrometria de massas mostrou que houve perdas significativas de monoterpenos durante o processo de secagem em estufa.
\end{abstract}

\section{INTRODUÇÃO}

A aroeira-vermelha (Schinus terebinthifolius Raddi) é nativa da América do Sul. No Brasil, esta espécie vegetal é conhecida por diversos nomes como, por exemplo, aroeira-dapraia, aroeira-pimenteira e pimenta-rosa (BAGGIO, 1988) e (LORENZI; MATOS, 2002). Apesar de ser uma espécie de pouco cultivo agrícola no Brasil (o produto é obtido diretamente de matas nativas), a aroeira-vermelha possui um grande potencial, para exploração e uso comercial, por apresentar propriedades medicinais, cosméticas e alimentícias (RODRIGUEZ; PAULA, 2009).

A literatura apresenta diversos estudos de propriedades da aroeira-vermelha, destacando suas propriedades cicatrizante, adstringente, anti-inflamatória, antimicrobiana e diurética. As partes utilizadas que apresentam tais propriedades são a casca do tronco, as folhas e os frutos (BORNHAUSEN, 2002 apud DEGÁSPARI; WASZCZYNSKYJ; SANTOS, 2004), (VASCONCELOS et al., 2005) e (BRANCO NETO et al., 2006). O óleo essencial da aroeiravermelha, encontrado em teores e composições variáveis nas suas partes vegetais, é o principal responsável por suas várias propriedades. Resultados de sua análise fitoquímica registraram a presença de alto teor de tanino, biflavonóides e ácidos triterpênicos nas cascas e de até $5,0 \%$ de óleo essencial formado por mono e sesquiterpenos nos frutos e nas folhas (LORENZI; MATOS, 2002). O fruto da aroeira-vermelha é uma fonte próspera de óleos essenciais, sendo que possui a melhor qualidade e o maior rendimento em comparação com as outras partes vegetais (CLEMENTE, 2006). Na extração de óleo essencial, a composição química e o rendimento do processo são influenciados por diversos fatores, como por exemplo as condições operacionais do processo e também as condições de pré-tratamento da matéria-prima.Deste modo, este trabalho teve por objetivo analisar a influência da secagem da matéria-prima na obtenção de óleo essencial de frutos da aroeira-vermelha. 


\section{MATERIAIS E MÉTODOS}

\subsection{Matéria-prima}

Os frutos de aroeira-vermelha (Schinus terebinthifolius Raddi) foram colhidos em junho de 2014, no município de Aracruz, Espírito Santo.Com o objetivo de identificar a espécie vegetal, foram coletados ramos com folhas e frutos para a confecção de exsicatas a serem depositadas em herbário. Os ramos, de aproximadamente $30,0 \mathrm{~cm}$, foram colocados entre folhas de papel absorvente e o conjunto foi prensado entre duas grades de madeira, sendo mantido ao sol para a secagem. Após a colheita, os frutos foram separados de impurezas (folhas, galhos, pedras, etc.) com o auxílio de peneiras metálicas de aberturas de 5,6 e $4,0 \mathrm{~mm}\left(\right.$ Granutest $^{\circledR}$ ), sendo que algumas partículas estranhas foram separadas manualmente. Todas as amostras foram acondicionadas em embalagens plásticas herméticas e foram mantidas em freezer, à temperatura em torno de $-18,0^{\circ} \mathrm{C}$, até o início dos ensaios.

\subsection{Secagem}

A secagem dos frutos de aroeira-vermelha foi realizada em uma estufa, com circulação de ar forçada (QUIMIS ${ }^{\circledR}$ ), na temperatura de $40,0{ }^{\circ} \mathrm{C}$ e até a massa constante. Após a secagem as amostras foram acondicionadas adequadamente e armazenadas em local seco e ao abrigo da luz. Para determinar o tempo de secagem foi realizado um estudo da cinética de secagem dos frutos na estufa, em triplicata. Nos ensaios, aproximadamente $30,0 \mathrm{~g}$ dos frutos $(2,0 \mathrm{~cm}$ de espessura) foram colocados em uma bandeja metálica. A amostra foi mantida na estufa a uma temperatura de $40,0{ }^{\circ} \mathrm{C}$, sendo a massa da amostra determinada, ao longo do tempo até a massa constante, em uma balança analítica $\left(\mathrm{BEL}^{\circledR}\right.$, precisão de $\left.0,0001 \mathrm{~g}\right)$. O teor de umidade foi determinado pelo Método da estufa a $105^{\circ} \mathrm{C}$ ( 24 horas), conforme as Regras para Análise de Sementes do Ministério da Agricultura, Pecuária e Abastecimento (BRASIL, 2009).

\subsection{Granulometria do sistema particulado}

Após a secagem, os frutos foram triturados em um liquidificador industrial (Waring Commercial $^{\circledR}$ ) durante 1 minuto, em potência máxima, e em bateladas de aproximadamente 200,0 g. Para que o diâmetro médio das partículas esteja incluído na faixa de 0,25 a 2,0 mm, todo o material trituradofoi classificado com o auxílio de uma peneira metálica de abertura de $1,68 \mathrm{~mm}\left(\right.$ Granutest $\left.^{\circledR}\right)$. O peneiramento foi realizado através de agitação manual, sendo que o material retido nesta peneira foi novamente triturado no liquidificador. Após as operações de preparo da matéria-prima, todas as amostras foram armazenadas em embalagens de plástico herméticas e protegidas da luz. O material foi mantido a $-18,0{ }^{\circ} \mathrm{C}$ em freezer até o momento dos ensaios. Para determinara granulometria do sistema particulado, uma amostra representativa do material triturado (cerca de 200,0 g) foi classificada de acordo com a série padrão de peneiras Tyler de 10 a 42 mesh (Granutest ${ }^{\circledR}$ ), utilizando um agitador de peneiras $\left(\right.$ Bertel $\left.^{\circledR}\right)$. O peneiramento foi realizado, primeiramente, através de uma agitação manual e depois utilizando o agitador de peneiras, em frequência máxima e por um tempo médio de 20 minutos. As massas retidas em cada peneira foram determinadas em uma balança semianalítica (SHIMADZU ${ }^{\circledR}$, precisão de $0,01 \mathrm{~g}$ ). O diâmetro médio geométrico das partículas $\left(d_{m g}\right)$ foi determinado de acordo com o método recomendado pela ASAE Standards (1997) através da Equação 1. 


$$
d_{m g}=\log ^{-1}\left(\frac{\sum_{i=1}^{n}\left(m_{i} \log \bar{d}_{i}\right)}{\sum_{i=1}^{n} m_{i}}\right)
$$

Em que $m_{i}$ é massa do material retido na i-ésima peneira e $\overline{d_{i}}$ é o diâmetro médio das partículas retidas na i-ésima peneira, calculado conforme a Equação 2.

$$
\overline{d_{i}}=\left(d_{i} \cdot d_{i-1}\right)^{0,5}
$$

Em que: $d_{i}$ é abertura nominal da i-ésima peneira, pela qual a partícula ficou retida; e $d_{i-1}$ é abertura nominal de uma peneira maior que a i-ésima peneira, pela qual a partícula passou.

\subsection{Hidrodestilação}

Os frutos triturados $(165,0 \mathrm{~g})$ foram colocados em um balão de fundo redondo de 2,0 L juntamente com 1,0 L de água destilada. Em seguida o balão foi adaptado ao aparelho Clevenger, sendo o sistema aquecido em manta de aquecimento e mantido em ebulição por 4,5 horas. Após o tempo pré-estabelecido, o óleo junto com a água (hidrolato), foi recolhido em um funil de separação e o aparelho de Clevenger foi lavado com diclorometano para a retirada de óleo essencial aderido à parede da vidraria. O produto da lavagem e o óleo essencial foram transferidos para um funil de separação, onde foram adicionados $30,0 \mathrm{~mL}$ de diclorometano (por três vezes). Em seguida a fase aquosa foi descartada e a fase contendo o óleo essencial junto com diclorometano foi recolhida em béquer para a retirada da água residual. Para isto, o sulfato de sódio anidro foi misturado em excesso e após alguns minutos em repouso, a mistura foi filtrada para a retirada do sulfato de sódio. $O$ filtrado foi levado ao rotaevaporador a $40,0{ }^{\circ} \mathrm{C}$ e pressão reduzida para remoção do diclorometano. Em seguida a massa do óleo essencial foi determinada em uma balança analítica, para o cálculo do rendimento do processo (base úmida e base seca). O óleo essencial foi colocado em frascos de vidro, cor âmbar e com tampa rosqueada e foram mantidos em freezer $\left(-18,0{ }^{\circ} \mathrm{C}\right)$ até o momento de sua utilização.

\subsection{Cromatografia gasosa acoplada à espectrometria de massas}

Neste trabalho a composição química doóleo essencial foi analisada por cromatografia gasosa acoplada à espectrometria de massas (CG-EM). As amostras foram analisadas em um sistema CG/EM (Agilent Technologies, modelo HP-6890, EUA) acoplada à espectroscopia de massas. O espectrômetro de massas (Agilent Technologies, modelo HP5975, EUA) operou com impacto de elétrons de $70,0 \mathrm{eV}$ e analisador quadrupole linear. A coluna capilar utilizada foi uma HP-5MS, 5,0 \% difenil, 95,0 \% dimetilpolisiloxano (modelo HP5MS $30 \mathrm{~m}$ x 0,25 $\mathrm{mm} \times 0,25 \mu \mathrm{m}$ de espessura de filme). $\mathrm{O}$ gás de arraste utilizado foi o hélio, com fluxo na coluna de $1,0 \mathrm{~mL} / \mathrm{min}$. As temperaturas do injetor e do detector foram $220,0^{\circ} \mathrm{C}$ e $250,0{ }^{\circ} \mathrm{C}$, respectivamente, sendo utilizada uma programação única de temperatura do forno de $60,0{ }^{\circ} \mathrm{C}$ a $240,0{ }^{\circ} \mathrm{C}$ e taxa de aquecimento de $3,0{ }^{\circ} \mathrm{C} / \mathrm{min}$. As amostras analisadas foram preparadas através de uma diluição de $10,0 \mathrm{mg}$ do produto em $1,0 \mathrm{~mL}$ de acetato de etila. Foi utilizado 


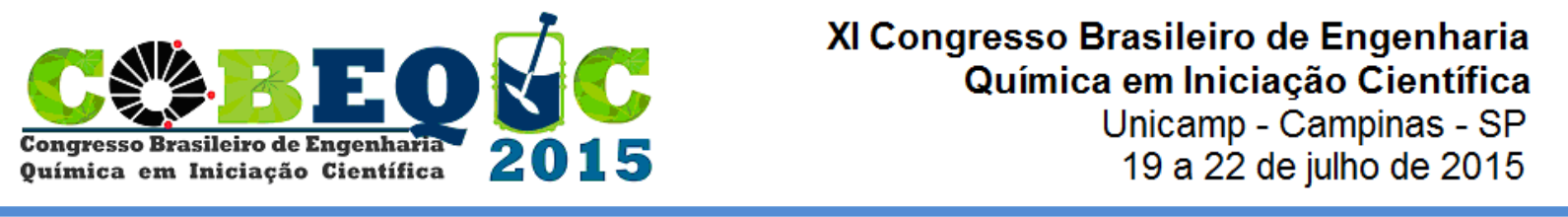

um injetor automático que inseria no sistema alíquotas de $1,0 \mu \mathrm{L}$ de cada amostra preparada com divisão de fluxo 30:1.

\section{RESULTADOS E DISCUSSÕES}

\subsection{Matéria-prima}

A Figura 1 apresenta as amostras da matéria-prima bruta e após a retirada das impurezas. O teor de umidade, em base seca, da matéria-prima é próximo de 69,4\% (desvio padrão de $0,6 \%$ ).

Figura 1 - Amostra de frutos de aroeira-vermelha: a) bruta; b) classificada

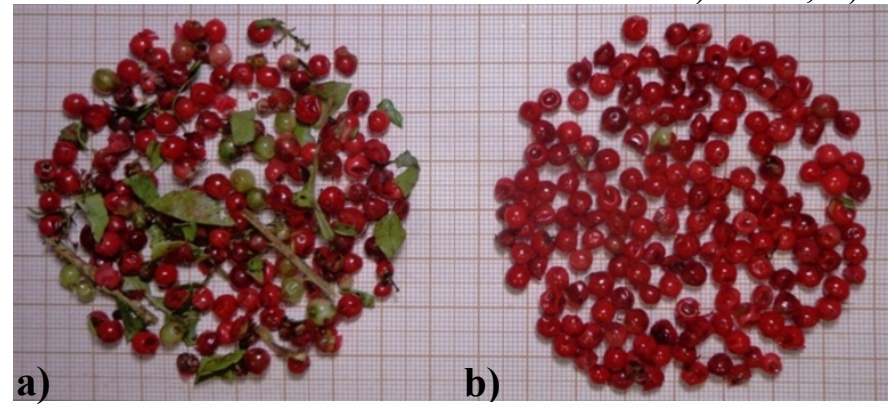

\subsection{Secagem}

Na Figura 2 é apresentada a cinética de secagem dos frutos de aroeira-vermelha na estufa, a uma temperatura de $40,0^{\circ} \mathrm{C}$ e umidade relativa do ar de secagem $(U R)$ de $24,0 \%$. No gráfico é apresentado o desvio padrão médio, relacionado ao teor de umidade, que é igual a 0,009 , o que indica repetibilidade nos ensaios da cinética de secagem. Através da análise da curva de cinética de secagem da Figura 2, determinou-se um tempo de secagem de 3 dias (72 $\mathrm{min}$ ), pois a partir deste período de secagem não se observou perdas de massa significativas no processo. Os frutos após o processo de secagem apresentaram um teor de umidade, em base seca, próximo de 7,0\%.

Figura 2 - Cinética de secagem para a temperatura de $40,0{ }^{\circ} \mathrm{C}$ e $U R=24,0 \%$

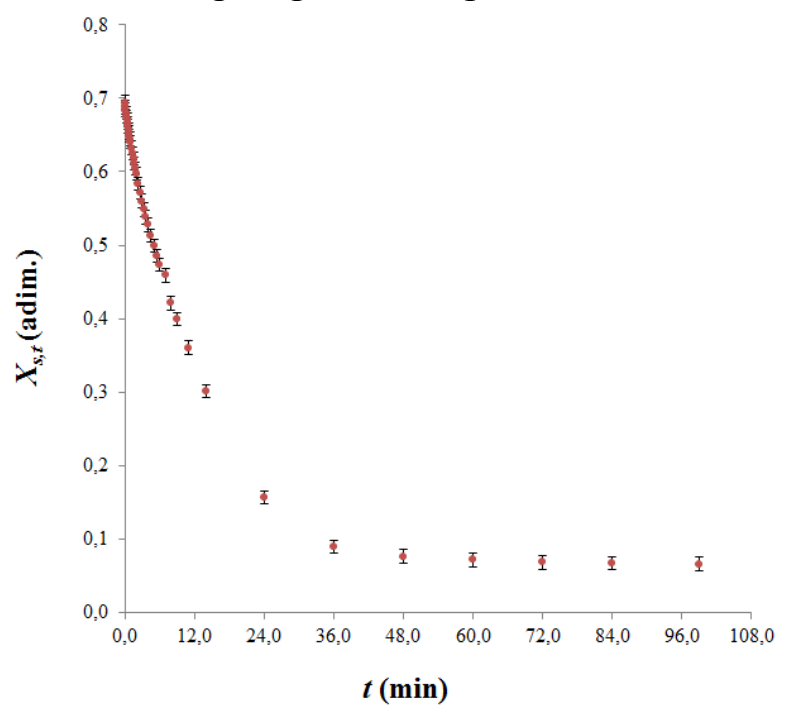




\subsection{Diâmetro médio da partícula}

A Tabela 1 apresenta a distribuição granulométrica obtida através do peneiramento de uma amostra representativa dos frutos triturados. Com base nos dados da Tabela 1, tem-se que a amostra dos frutos de aroeira-vermelha triturados apresentou um diâmetro médio geométrico das partículas $\left(d_{m g}\right)$ igual a $0,916 \mathrm{~mm}$.

Tabela 1 - Especificações das faixas de diâmetro médio da partícula

\begin{tabular}{|c|c|c|c|c|}
\hline \multirow[b]{2}{*}{ Faixa } & \multicolumn{3}{|c|}{ Abertura da peneira } & \multirow[b]{2}{*}{$F_{i}(\%)$} \\
\hline & Tyler (mesh) & $\begin{array}{c}-d_{i-1}+d_{i} \\
(\mathbf{m m})\end{array}$ & $\overline{d_{t}}(\mathbf{m m})$ & \\
\hline$\overline{f_{1}}$ & $-10+12$ & $-1,680+1,410$ & 1,539 & 0,205 \\
\hline$f_{2}$ & $-12+14$ & $-1,410+1,190$ & 1,295 & 7,956 \\
\hline$f_{3}$ & $-14+16$ & $-1,190+1,000$ & 1,091 & 34,284 \\
\hline$f_{4}$ & $-16+20$ & $-1,000+0,841$ & 0,917 & 17,053 \\
\hline$f_{5}$ & $-20+24$ & $-0,841+0,707$ & 0,771 & 34,018 \\
\hline$f_{6}$ & $-24+28$ & $-0,707+0,595$ & 0,649 & 2,970 \\
\hline$f_{7}$ & $-28+32$ & $-0,595+0,500$ & 0,545 & 3,046 \\
\hline$f_{8}$ & $-32+35$ & $-0,500+0,420$ & 0,458 & 0,251 \\
\hline$f_{9}$ & $-35+42$ & $-0,420+0,354$ & 0,386 & 0,217 \\
\hline
\end{tabular}

Em que: $F_{i}$ é a fração mássica do material retido na i-ésima peneira.

\subsection{Hidrodestilação}

Na Tabela 2 são apresentados os rendimentosem base seca e base úmida de todos os ensaios de hidrodestilação.

Tabela 2 - Resultados dos rendimentos do processo de hidrodestilação

\begin{tabular}{lccc}
\hline & & $\begin{array}{c}\text { Rendimento em } \\
\text { base úmida }(\%)\end{array}$ & $\begin{array}{c}\text { Rendimento em } \\
\text { base seca }(\%)\end{array}$ \\
\hline \multirow{4}{*}{ Frutos in natura } & 1 & 4,02 & 6,67 \\
& 2 & 4,04 & 6,71 \\
& 3 & 4,23 & 7,02 \\
Frutos secos & Média & $\mathbf{4 , 0 9}$ & $\mathbf{6 , 8 0}$ \\
& Desvio padrão & 0,1 & 0,2 \\
\hline & 1 & 3,47 & 3,7671 \\
& 3 & 3,84 & 4,1747 \\
& Média & 3,92 & 4,2523 \\
& Desvio padrão & $\mathbf{3 , 7 4}$ & $\mathbf{4 , 0 6}$ \\
\end{tabular}

Conforme observado na Tabela 2, os maiores rendimentos foram obtidos quando se utilizou os frutos da aroeira-vermelha in natura (sem o processo de secagem), visto que a diferença observada no rendimento em base seca é de aproximadamente 2,74\%. Ainda em relação aos frutos in natura, observamos que o rendimento médio em base úmida é 2,71\% 
inferior ao rendimento médio em base seca, enquanto para os frutos secos essa diferença é de apenas 0,32 \%, como já esperado. Segundo Bandoni (2000) a produção de óleo essencial depende de vários fatores: estado fenológico, fatores geográficos (localização), fatores ecológicos (habitat), variabilidade genética, o processo de extração, etc. Devido a estes fatores, os dados apresentados na Tabela 2 difere dos resultados publicados por Silva et al. (2005) e Nicolini, Puget e Mazza (2009), que realizaram a hidrodestilação dos frutos de aroeira-vermelha e obtiveram rendimentos de $4,6 \%$ e $2,6 \%$, respectivamente. Os resultados da cromatografia revelaram que houve perdas significativas de monoterpenos durante $o$ processo de secagem em estufa a $40,0^{\circ} \mathrm{C}$. O óleo essencial obtido a partir dos frutos in natura apresentou um teor de monoterpenos de $83,42 \%$ e teor de sesquiterpenos de $16,58 \%$. Já o produto obtido a partir dos frutos secos apresentou um teor de monoterpenos igual a 76,01\% e de sesquiterpenos igual a $23,99 \%$. É válido ressaltar que na continuidade deste trabalho todos os componentes do óleo essencial serão identificados.

\section{CONCLUSÕES}

Os resultados revelaram que os maiores rendimentos do óleo essencial foram obtidos quando se utilizou os frutos in natura. A análise de cromatografia gasosa acoplada à espectrometria de massas mostrou que houve perdas significativas de monoterpenos durante $\mathrm{o}$ processo de secagem em estufa. Em relação ao processo de secagem, foi observado que o tempo ideal para a secagem, a $40{ }^{\circ} \mathrm{C}$, é de 3 dias. Após esse período, não foram observadas perdas de massa significativas.

\section{NOMENCLATURA}

$d_{i}$ : abertura nominal da i-ésima peneira, pela qual a partícula ficou retida

$d_{i-1}$ : abertura de uma peneira maior que a i-ésima peneira, pela qual a partícula passou

$\overline{d_{\mathrm{L}}}$ : diâmetro médio das partículas retidas na i-ésima peneira

$d_{m g}:$ diâmetro médio geométrico

$F_{i}$ : fração mássica do material retido na i-ésima peneira

$m_{i}$ : massa do material retido na i-ésima peneira

$U R$ : umidade relativa do ar de secagem

\section{REFERÊNCIAS}

BANDONI, A. L. Los Recursos Vegetales Aromáticos enLatinoamérica. Editorial de laUniversidad Nacional de La Plata: Argentina. (2000).

A.S.A.E. Standards. Method of Determining and Expressing Fineness of Feed Materials by Sieving. ASAE, S319.3, St. Joseph, MI, 1997, p. 547. 
BAGGIO, A. J. Aroeira como potencial para usos múltiplos na propriedade rural. Boletim de Pesquisa Florestal, Colombo, n.17, p.25-32, 1988.

BRANCO NETO, M. L. C. et al. Avaliação do extrato hidroalcoólico de Aroeira (SchinusterebinthifoliusRaddi) no processo de cicatrização de feridas em pele de ratos. Acta Cirúrgica Brasileira, [S.1.], v.21, n.2, p.17-22, 2006. Disponível em: < http://www.scielo.br/pdf/acb/v21s2/32158.pdf>. Acesso em: 18 jan. 2014.

BRASIL. Ministério da Agricultura, Pecuária e Abastecimento. Regras para análise de sementes. Ministério da Agricultura, Pecuária e Abastecimento. Secretaria de Defesa Agropecuária. Brasília, DF: Mapa/ACS, 2009. 395p. ISBN 978-8-99851-70-8. Disponível em: < http://www.bs.cca.ufsc.br/publicacoes/regras\%20analise\%20sementes.pdf $>$. Acesso em: 25 jan. 2012.

CLEMENTE, A. D. Composição química e atividade biológica do óleo essencial da pimenta-rosa (SchinusterebinthifoliusRaddi). 2006. 63 f. Tese (Doutorado em Agroquímica) Universidade Federal de Viçosa, Viçosa, 2006.

DEGÁSPARI, C. H.; WASZCZYNSKYJ, N.; SANTOS, R. J. Atividade antioxidante de extrato de fruto de aroeira (SchinusterebenthifoliusRaddi). Visão Acadêmica, Curitiba, v. 5, n. 2, p. 83-90, 2004. ISSN 1518-5192.

LORENZI, H.; MATOS, F. J. A. Plantas medicinais no Brasil: nativas e exóticas. Nova Odessa, SP: Instituto Plantarum, 2002. 512p.

NICOLINI, J. V.; PUGET, F. P.; MAZZA, M. G. G. Avaliação da eficiência de extração de óleo essencial de SchinusterebinthifoliusRaddi (aroeira-vermelha) pelos métodos de hidrodestilação e arraste a vapor. In: CONGRESSO BRASILEIRO DE ENGENHARIA QUÍMICA EM INICIAÇÃO CIENTÍFICA, 8., 2009, Uberlândia. Anais eletrônico. Uberlândia: $\quad$ UFU, $2009 . \quad$ p.1-5. Disponível $<$ http://www.cobeqic2009.feq.ufu.br/uploads/media/99317061.pdf $>$. Acesso em: 15 jan. 2013.

RODRIGUEZ, E. M.; PAULA, R. C. Variabilidade de germinação e condutividade elétrica em sementes de aroeira-pimenteira (SchinusterebinthifoliusRaddi). In: CONGRESSO DE INICIAÇÃO CIENTÍFICA DA UNESP, 21., 2009, São José do Rio Preto. Índice geral dos resumos do XXI CIC. São José do Rio Preto: UNESP, 2009, p. 1995-1998. ISBN 97885-88792-08-1. Disponível em: <http://prope.unesp.br/xxi_cic/27_32306112843.pdf $>$. Acesso em: 15 jan. 2014.

SILVA, L. V. et al. Extração do óleo essencial da pimenta rosa (Schinusmolle) usando hidrodestilação e soxhlet. In: CONGRESSO BRASILEIRO DE ENGENHARIA QUÍMICA EM INICIAÇÃO CIENTÍFICA, 6., 2005, Campinas. Anais eletrônico. Campinas: UNICAMP, 2005. p.1-7. Disponível em: <http://www.feq.unicamp.br/ cobeqic/top14.pdf $>$. Acesso em: 15 jan. 2013.

VASCONCELOS, E. A. F. et al. Influência da temperatura de secagem e da concentração de Aerosil®200 nas características dos extratos secos por aspersão da 
XI Congresso Brasileiro de Engenharia Química em Iniciação Científica Unicamp - Campinas - SP 19 a 22 de julho de 2015

SchinusterebinthifoliusRaddi (Anacardiaceae). Revista Brasileira de Farmacognosia, [S.1.], v.15, n.3, p. 243-249, 2005. ISSN 0102-695X. 